\title{
Produtos naturais no controle de Colletotrichum sp. associado a pimenta-de- cheiro (Capsicum chinense Jacq.)
}

\section{Natural products in the control of Colletotrichum sp. associated with sweet pepper (Capsicum chinense Jacq.)}

\author{
Rosendo Galileo López Macedo \\ Universidade Federal do Amazonas \\ E-mail: galileolopezagro@gmail.com \\ OrcID: https://orcid.org/0000-0002-3341-8564 \\ Jânia Lília da Silva Bentes \\ Universidade Federal do Amazonas \\ E-mail: jlbentes@ufam.edu.br \\ OrcID: https://orcid.org/0000-0001-7302-5661 \\ Antônia Queiroz Lima Souza \\ Universidade Federal do Amazonas \\ E-mail: antoniaqlsouza@gmail.com \\ OrcID: https://orcid.org/0000-0001-5602-8617
}

Resumo: A pimenta-de-cheiro (Capsicum chinense Jacq.) é uma hortaliça muito consumida no Estado do Amazonas, cultivada principalmente por pequenos produtores. A expansão da cultura é fortemente afeta pela ocorrência da antracnose, doença causada pelo fungo Colletotrichum sp., sendo o principal problema fitossanitário na cultura na região, podendo alcançar $100 \%$ de incidência. O controle é feito por meio de práticas culturais e uso de fungicidas. Este trabalho teve como objetivo avaliar o potencial do extrato aquoso de três espécies vegetais, Curcuma longa, Croton cajucara e Piper marginatum no desenvolvimento de Colletotrichum sp. in vitro, e na redução da incidência da doença em frutos de pimenta-de-cheiro. Foram utilizados os extratos aquosos obtidos a frio e a quente de cada espécie vegetal, para avaliar o crescimento micelial e a produção de conídio em meio de cultura BDA. O efeito dos extratos na redução da incidência da doença foi avaliado em frutos destacados, pulverizados com os extratos antes e após a inoculação com o fitopatógeno. Não foi observado efeito dos extratos no crescimento micelial e na esporulação do fungo em meio de cultura. Em frutos destacados houve redução da incidência da doença, quando os extratos foram aplicados de forma preventiva, podendo ter potencial para uso como uma medida complementar para o manejo da doença.

Palavras-chave: Antracnose. Extrato vegetal. Manejo alternativo.

Abstract: The sweet pepper (Capsicum chinense Jacq.) is a vegetable widely consumed in the State of Amazonas, cultivated mainly by small producers. The expansion of the culture is strongly affected by the occurrence of anthracnose, a disease caused by the fungi Colletotrichum sp., being the main phytosanitary problem of the crop in the region. The disease management is done by cultural practices and use of fungicides. The goal of this work was to evaluate the potential of aqueous extracts from three plant species, Curcuma longa, Croton cajucara and Piper marginatum on the Colletotrichum sp. development in vitro and on the reduction of anthracnose incidence on sweet pepper fruits. Cold and hot extract from each plant species were used to evaluate the mycelial development and conidia production on BDA culture media. The effect of the extracts on the disease incidence was evaluated on sweet pepper fruits, sprayed before and after inculation with de phytopathogen. No effect was observed on mycelial development and fungi sporulation on culture media. There was a reduction of disease incidence on fruits, when the extract was sprayed as preventive treatment, and it may have use as complementary measure for disease management.

Keywords: Anthracnose. Alternative management. Plant extract. 


\section{Introdução}

As pimentas (Capsicum spp.) estão entre as principais hortaliças cultivadas no mundo, podendo ser consumidas in natura ou processadas em forma de páprica, pastas, desidratadas, em conservas (Aguilar et al., 2020). Segundo a Organização das Nações Unidas para a Alimentação (FAO, 2019) o maior produtor de pimenta do gênero Capsicum no mundo é a China com uma produção de 12,656,804.92 t. No Brasil, segundo o Instituto Brasileiro de Geografia e Estatística (IBGE, 2017) a produção de pimentas foi de $46.702 \mathrm{t}$. sendo o estado do Pará o maior produtor com $18.048 \mathrm{t}$.

No Amazonas as pimentas de cheiro (C. chinense Jacq. 1777) são amplamente cultivadas devido a seu sabor pungente e aroma agradável proporcionados pelos capsaicinóides (Sganzerla, Coutinho, Melo, \& Godoy, 2014), é fonte de renda para pequenos produtores possibilitando a continuidade da atividade agrícola e manutenção no campo evitando o êxodo rural (Berni \& Cardoso, 2013). Segundo o último relatório da produção vegetal do Instituto de Desenvolvimento Agropecuário e Florestal Sustentável do Estado do Amazonas (IDAM, 2019) a estimativa de área plantada de pimenta-de-cheiro foi $1.397,21$ ha e produção estimada foi de $6.546,08 \mathrm{t}$.

O cultivo de pimenta-de-cheiro pode ser atacado por diversos microrganismos causadores de doenças como, nematoides, bactérias e fungos, sendo a antracnose, causada pelo fungo Colletotrichum spp., a principal doença da cultura no Amazonas, podendo levar a $100 \%$ de perdas na produção (Hanada, Gasparotto, Perira, \& Assis, 2011). A doença pode atacar todas as variedades comerciais existentes se não forem adotadas medidas de controle (Gasparotto, Pereira, \& Berni, 2014). Os sintomas ocorrem em ramos e folhas sendo os frutos as partes mais afetadas por lesões inicialmente pequenas e escuras, circulares e deprimidas, que progridem formando círculos concêntricos e pontos negros que corresponde aos acérvulos do fungo de onde surge uma massa alaranjada constituída pelos conídios do fungo (Hanada et al., 2011).

Diversas espécies de Colletotrichum são relatadas causando antracnose em pimentas como: $C$. truncatum, C. gloeosporioides, C. fructicola, C. siamense C. brevisporum, C. scovillei, C. sichuanensis (Liu et al., 2016; Ranathunge, Mongkolporn, Ford, \& Taylor, 2012), C. acutatum (Suwor, Thummabenjenjapane, Sanitchon, Kumar, \& Techawongstien, 2015), C. coccodes, (Sharma, Katoch, \& Sharma, 2011) C. dematium (Shin, Xu, Zhang, \& Cheng, 2000), C. boninense (Diao et al., 2013) e C. cliviae (Saini, Gupta, \& Anandalakshmi, 2017). No Amazonas três espécies foram descritas afetando a pimenta-de-cheiro: $C$. siamense, C. scovillei, (Oliveira, Matos, Albuquerque, Hanada, \& Silva, 2017) e C. brevisporum (Almeida, Matos, Assis, \& Hanada, 2017).

Para o controle da doença são recomendadas práticas culturais como o uso de sementes certificadas, plantio menos adensado, eliminação de restos de cultura, rotação de cultura com espécie de planta não hospedeira do fungo (Ali, Bordoh, Singh, Siddiqui, \& Droby, 2016) além do controle químico com produtos registrados no Ministério de Agricultura Pecuária e Abastecimento (MAPA, 2021), uma vez que não existem cultivares resistentes disponíveis. O uso consecutivo de produtos com o mesmo mecanismo de ação aliado ao uso indiscriminado de fungicidas oferece risco a saúde e danos ao ambiente além da seleção de variantes resistentes aos princípios ativos utilizados (Tyskiewicz et al., 2019; Martinez, Gomez, Ramirez, Gil, \& Durango, 2020).

Uma abordagem menos prejudicial para o controle de doenças em plantas de importância agrícola, é a adoção de extratos derivados de plantas que apresentam compostos quimicamente ativos contra fitopatógenos (Wang, Zhang, Sun, \& Zhang, 2017). Estes compostos bioativos são derivados de metabolitos secundários produzido pelas plantas como alcaloides, fenóis, flavonóides e terpenóides, (Sun, Wang, Han, Zhang, \& Feng, 2017). Diversos compostos bioativos tem sido isolados por métodos fitoquímicos ou bioquímico e testados para observar o efeito dos extratos sob condições controladas in vitro no desenvolvimento do patógeno, mostrando eficiência no controle, alterando o desenvolvimento patogênico totalmente ou em parte (Nazzaro, Fratianni, Coppola, \& De Feo, 2017; Park et al., 2017).

Experimentos em casa de vegetação ou em condições de campo, os extratos vegetais mostram a eficiência na redução da severidade da doença, seja pela ação do composto diretamente sob o patógeno ou como elicitor estimulando resistência induzida na planta (Ali, Pheng, \& Mustafa, 2015; Meng, Li, Bi, Zhu, \& $\mathrm{Ma}, 2015)$, resultando na redução dos sintomas de doenças ou em um fenótipo de resistência, sem o uso de agrotóxicos. 
No Brasil existe uma diversidade de espécies vegetais com potencial de serem exploradas e utilizadas para o controle de fungos fitopatogênicos. As espécies de plantas como Croton cajucara Benth. Piper marginatum Jacq. e Curcuma longa Linn. são plantas exploradas na medicina tradicional no tratamento de doenças em humanos. A espécie $C$. cajucara é um arbusto nativo da floresta Amazônica pertencente à família Euphorbiaceae, popularmente conhecida como sacaca, e é utilizada na medicina tradicional através da ingestão oral da infusão ou cocção de suas folhas ou cascas, para tratamento de úlceras gástricas, distúrbios hepáticos, diabetes, febre e malária (Nascimento et al., 2017, Azevedo et al., 2014). Suas propriedades medicinais estão relacionadas a presença de terpenos como linalol e 7-hidroxicalameneno. Esta espécie também tem demonstrado efeito antimicrobiano, como relatado por Azevedo et al. (2016) onde o uso de 7-hidroxicalameneno em concentrações de 39,06, a 78,12 $\mu \mathrm{g} \cdot \mathrm{mL}^{-1}$, inibiu o crescimento das leveduras Candida albicans, C. dubliniensis e C. parapsilosis causadoras de infecções na corrente sanguínea em seres humanos.

A planta $P$. marginatum. pertence à família Piperaceae, é um arbusto aromático com pecíolo alado e as folhas em forma de coração, que são as duas principais características que facilitam a sua identificação. Encontra distribuída no Centro e Sul das Américas, e no Brasil é conhecido como pimenta de macaco e o extrato das folhas é utilizada para tratamento de doenças gastrointestinais, reumatismo e tumores, (Bru \& Guzman, 2016;). Esta espécie tem sido relatada como potencial agente de biocontrole de fungos e bactérias fitopatogênicas. Araújo et al. (2014), usando o extrato metanólico de $P$. marginatum, observou a inibição de $82,4 \%$ do crescimento micelial e $81,2 \%$ do diâmetro da lesão em frutos de pimentão causado pelo fitopatógeno Colletotrichum scovillei.

A espécie Cur. longa, pertence à família Zingiberaceae, é uma erva perene originaria das regiões tropicais da Ásia. O rizoma é o órgão mais utilizado da planta dando cor e sabor aos alimentos, e na medicina tradicional da Ásia para o tratamento de doenças gastrointestinais e hepáticas, doenças de pele, infecções e problemas ginecológicos (Pagano, Romano, Izzo, \& Borrelli, 2018). As móleculas ativas mais abundantes da cúrcuma são os curcuminóides, compostos polifenólicos, que estão relacionados aos efeitos farmacológicos de interesse terapêutico. A C. Dorneles et al. (2018) observaram que o extrato de Cur. longa inibiu $60 \%$ do crescimento micelial e $83,34 \%$ da esporulação do Bipolaris oryzae causador da mancha- parda em plantas de arroz.

Em função do potencial já demostrado no controle de microrganismos por estas espécies vegetal, o objetivo deste trabalho foi avaliar o uso de extratos de $C$. cajucara, $P$. marginatum e Cur. longa, e no controle de Colletotrichum sp. in vitro e na redução da incidência da antracnose em frutos de pimenta-de-cheiro.

\section{Material e Métodos}

\subsection{Coleta do material vegetal}

Para a obtenção dos extratos vegetais, amostras de folhas de $C$. cajucara, $P$. marginatum e de rizomas de Cur. longa , foram coletadas no período da manhã, no setor sul da Universidade Federal do Amazonas (UFAM), coordenadas geográficas -3.101623 Sul e -59.976167 Oeste, em sacos de papel, etiquetadas e transportadas ao laboratório de Fitopatologia onde foram lavadas em água corrente, colocadas para secar em temperatura ambiente $\left( \pm 26^{\circ} \mathrm{C}\right)$ durante $24 \mathrm{~h}$, seguida de secagem em estufa de ventilação forçada a $70{ }^{\circ} \mathrm{C}$ durante $48 \mathrm{~h}$. Após a secagem o material foi triturado em moinho de quatro lâminas até a obtenção de um pó seco.

\subsection{Obtenção dos extratos vegetais a frio e a quente}

Para o preparo do extrato frio (EF), $50 \mathrm{~g}$ de cada material vegetal seco e triturado foi adicionado a 500 $\mathrm{mL}$ de água destilada esterilizada em erlenmeyer de $1 \mathrm{~L}$, homogeneizado e deixado em repouso durante $48 \mathrm{~h}$, em temperatura ambiente $\left( \pm 26{ }^{\circ} \mathrm{C}\right)$. Para o preparo do extrato quente $(E Q), 50 \mathrm{~g}$ de cada material vegetal nas mesmas condições citadas anteriormente, foi homogeneizado em água destilada esterilizada à temperatura de $70{ }^{\circ} \mathrm{C}$, e deixado em repouso durante $2 \mathrm{~h}$.

Após o período de repouso do EF e EQ, foi feita uma filtragem em camada dupla de gaze, e uma segunda filtragem em papel de filtro. Os extratos filtrados foram centrifugados em tubos Falcon de $50 \mathrm{~mL}$ a $5000 \mathrm{rpm}$ durante $10 \mathrm{~min}$ e o sobrenadante foi submetido a esterilização por filtragem em membrana 
Milipore ${ }^{\circledR}$ de $0,45 \mu \mathrm{m}$ de porosidade. Os EF e EQ obtidos foram armazenados em congelador a temperatura de $-18{ }^{\circ} \mathrm{C}$.

\subsection{Obtenção do isolado de Colletotrichum sp.}

O isolado de Colletotrichum sp. foi obtido a partir de frutos de pimenta-de-cheiro apresentando sintomas típicos da antracnose, coletados em uma propriedade rural produtora, localizada no $\mathrm{km} 24 \mathrm{da}$ Rodovia BR 174 em Manaus-AM. Os frutos foram depositados em sacos de papel, etiquetados e transportados para o laboratório, onde foi realizado o isolamento indireto do fitopatógeno em placas de petri contendo meio de cultura BDA (batata-dextrose-ágar) (KASVI). A identificação morfológica do fitopatógeno foi realizada pela observação de estruturas reprodutivas, em lâminas de microscopia contendo corante azul de algodão $1 \%$ em lactofenol, com auxílio de um microscópio ótico (Zeiss®) sob objetiva de 40X.

\subsection{Efeito dos extratos sobre o crescimento micelial e produção de conídios de Colletotrichum sp.}

Os efeitos dos EF e EQ de folhas de C. cajucara, $P$. marginatum e dos rizomas de Cur. longa , foram avaliados em dois experimentos separados, sendo um para o extrato frio (EF) e outro para extrato quente (EQ). Nestes foram quantificados o crescimento micelial e a produção de conídios do fungo em placas de petri de $60 \mathrm{~mm}$ de diâmetro, contendo meio de cultura BDA (KASVI) acrescido dos EF e EQ das espécies vegetal, nas concentrações de $10 \%, 20 \%$ e $30 \%$. No centro de cada placa foi depositado um disco de meio de cultura de $5 \mathrm{~mm}$ de diâmetro contendo a colônia do fungo Colletotrichum sp. As placas foram mantidas em câmara de crescimento (Tecnal), em temperatura de $27^{\circ} \mathrm{C}$

A avaliação do crescimento micelial foi realizado pela tomada das medidas diametralmente opostas da colônia a cada $24 \mathrm{~h}$, com auxílio de um paquímetro digital (Carbografite), até que a colônia de um dos tratamentos alcançasse a borda da placa. Após finalizada avaliação do crescimento micelial, as mesmas placas contendo as colônias do fungo, foram usadas para a quantificação da produção conídios, a partir de uma suspensão de esporos obtida de cada placa. A quantificação da esporulação foi feita com auxílio de um hemacitômetro e observado em objetiva de 40X em microscópio ótico (Zeiss).

O ensaio experimental foi em delineamento inteiramente casualizado (DIC) com nove tratamentos, (três espécies vegetal e três concentrações de cada extrato vegetal), com cinco repetições, sendo cada unidade experimental uma placa de Petri. Como testemunha foram usadas placas contendo somente o meio de cultura BDA. Os dados da produção de conídios foram transformados a $\log ^{10}$ para análise de variância. Com os dados obtidos foi realizada a análise de variância (ANOVA), e com as medias foram realizado o teste de Tukey a 5\% de probabilidade no Software R Studio Versão 4.0.2 (RStudio, 2020).

\subsection{Efeito dos extratos vegetais frio (EF) na incidência da antracnose em frutos destacados de pimenta-de cheiro (Capsicum chinense)}

Foram realizados dois experimentos separadamente visando avaliar o efeito preventivo e curativo dos extratos aquosos das folhas de $C$. cajucara e $P$. marginatume do rizoma de Cur. longa na incidência da antracnose em frutos destacados de pimenta-de-cheiro.

Frutos sadios e sem danos visíveis foram obtidos em propriedades rurais produtoras localizados na comunidade Boa Esperança (Rodovia BR 174 km 120, Presidente Figueiredo-AM, Brasil). Os frutos foram lavados em água corrente e desinfestados em álcool $70 \%$ por 5 min., hipoclorito de sódio por 2 min. seguido de três lavagens em água destilada autoclavada a 1 ATM por 20 min. e secos em papel toalha autoclavado nas mesmas condições citadas anteriormente. Após a assepsia, foram depositados três frutos em caixas plásticas tipo Gerbox ${ }^{\circledR}$, previamente lavadas e desinfestadas com álcool $70 \%$ e em luz ultravioleta (UV) durante $20 \mathrm{~min}$, e forradas com camada dupla de papel de filtro autoclavado e umedecido com $10 \mathrm{~mL}$ de água destilada autoclavada. Para avaliação do efeito preventivo, os extratos foram pulverizados sobre os frutos 48 h. antes da inoculação do fitopatógeno. Para avaliar o efeito curativo, os frutos foram inicialmente inoculados com o fitopatógeno e $48 \mathrm{~h}$. após a inoculação foram aplicados os extratos separadamente. A inoculação foi realizada pela aplicação por aspersão de uma suspensão de conídios de Colletotrichum sp. na concentração de $10^{5}$ conídios. $\mathrm{mL}^{-1}$, na superfície dos frutos. Após a aplicação dos tratamentos, os frutos foram mantidos em Gerbox ${ }^{\circledR}$ tampados, em temperatura ambiente $\left( \pm 26^{\circ} \mathrm{C}\right)$ durante seis dias. A avaliação foi feita pela quantificação da incidência da doença, uma vez que uma única infecção inviabiliza a comercialização do 
fruto, usando a formula: ID $(\%)=[$ (número de frutos doentes/número total de frutos avaliados $) \times 100]$ (Wheeler, 1969).

O experimento foi em delineamento inteiramente casualizado com três tratamentos (extratos vegetais aquosos de três espécies) e quatro repetições, sendo a unidade experimental um Gerbox ${ }^{\circledR}$ contendo três frutos. Como testemunhas foram utilizados frutos pulverizados com água destilada autoclavada (controle -) e frutos inoculados com patógeno (controle + ).

\section{Resultados}

Nos experimentos com os EF e EQ não houve diferença significativa do crescimento micelial e na produção dos conídios entre os tratamentos de acordo om o teste de Tukey a $5 \%$ de probabilidade. Os EF e EQ de Cur. longa na concentração de $30 \%$ proporcionaram o menor crescimento das colônias, não diferindo estatisticamente da testemunha. A menor produção de conídios foi observada no tratamento com Cur. longa na concentração de $20 \%$ do EQ. (Tabela 1). As espécies de C. cajucara, P. marginatum e Cur. longa não tiveram efeito significativo sobre o desenvolvimento de Colletotrichum $\mathrm{sp}$. quando os metabolitos das plantas foram extraídos com água nas duas condições experimentais.

Tabela 1. Efeito das diferentes concentrações do extrato frio (EF) e extrato quente (EQ), obtidos dos rizomas e folhas, de Curcuma longa, Croton cajucara e Piper marginatum, sobre o crescimento micelial e produção de conídios de Colletotrichum sp, in vitro.

\begin{tabular}{|c|c|c|c|c|c|}
\hline \multirow{2}{*}{ Tratamentos } & \multirow{2}{*}{$\begin{array}{l}\text { Concentração } \\
\text { extrato vegetal (\%) }\end{array}$} & \multicolumn{2}{|c|}{ Diâmetro da colônia (mm) } & \multicolumn{2}{|c|}{ Esporulação } \\
\hline & & Extrato & Extrato & Extrato & Extrato \\
\hline C. cajucara & 10 & $41,8 \mathrm{abc}$ & $40,0 a$ & $4,5 a b$ & $4,8 a$ \\
\hline C. cajucara & 20 & $44,0 \mathrm{abc}$ & 37,0 a & $4,9 a b$ & $4,1 \quad b c$ \\
\hline C. cajucara & 30 & $41,4 a b c$ & 38,0 a & $4,6 a b$ & 3,9 \\
\hline P. marginatum & 10 & $44,6 a b c$ & 44,3 a & $4,8 \mathrm{a}$ & $4,6 a b$ \\
\hline P. marginatum & 20 & $40,5 a b c$ & 42,8 a & $4,4 a b$ & $4,2 a b c$ \\
\hline P. marginatum & 30 & $39,7 \mathrm{bc}$ & 38,0 a & $4,6 a b$ & 4,0 bc \\
\hline Cur. longa & 10 & $42,2 a b c$ & $41,7 \mathrm{a}$ & $3,9 \mathrm{~b}$ & $4,1 a b c$ \\
\hline Cur. longa & 20 & $39,7 \mathrm{bc}$ & $37,9 a$ & $4,3 a b$ & $3,2 \quad c$ \\
\hline Cur. longa & 30 & $37,9 \mathrm{c}$ & $37,3 a$ & $4,3 a b$ & 4,1 bc \\
\hline BDA & 0 & $42,6 a b c$ & 43,8 a & $4,3 a b$ & $3,2 a b c$ \\
\hline C.V\% & & 9,51 & 9,65 & 7,89 & 15,47 \\
\hline
\end{tabular}

Medias seguidas pela mesma letra minúsculas na coluna não diferem estatisticamente pelo teste de Tukey a $5 \%$. EF= Extrato Frio; EQ= Extrato Quente.

Os EF foram testados de forma curativa e preventiva em frutos destacados de pimenta-de-cheiro para avaliar o efeito sobre a incidência da antracnose. Frutos que receberam tratamento curativo com extratos de Cur. longa e $P$. marginatum a incidência da doença foi de $100 \%$, e para C. cajucara foi $83,3 \%$. Os frutos que receberam tratamento preventivo com os extratos de Cur. longa, $P$. marginatum e $C$. cajucara a incidência foi de $0 \%, 33,3 \%$ e $41,7 \%$ inferior ao do controle positivo respectivamente (Tabela 2).

Tabela 2. Efeito curativo e preventivo dos extratos frios (EF) de Curcuma longa, Croton cajucara e Piper marginatum na incidência da antracnose em frutos destacados de pimenta-de-cheiro.

\begin{tabular}{ccc} 
Tratamento & \multicolumn{3}{c}{ Incidência (\%) } \\
\cline { 2 - 3 } Controle (-) & Curativo & Preventivo \\
Controle (+) & 0 & 0 \\
Cur. longa & 100 & 100 \\
P. marginatum & 100 & 0 \\
C. cajucara & 100 & 33,3 \\
\end{tabular}

\section{Discussão}


$O$ efeito não significativo dos EF e EQ no desenvolvimento in vitro do fitopatógeno pode estar relacionado com o método de extração utilizado. É possível que a extração dos metabólitos secundários de Cur. longa, $C$. cajucara e $P$. marginatum, somente com água não seja a forma mais eficiente para liberar os compostos com atividade antimicrobiana presentes nessas plantas, e que possivelmente estes metabólitos não tenham afinidade por solventes polares como a água.

Pesquisas mostram que algumas plantas têm seus metabólitos antimicrobianos extraídos com solventes polares, como a água, resultando em efeitos inibitórios no desenvolvimento de microrganismos patogênicos, no entanto, outras apresentam atividade inibitória dependente do solvente apolares ou de média polaridade utilizados na obtenção dos extratos e da concentração testada, (Mohsan, Ali, Shahbaz, Saeed, \& Burhan, 2017; Ezeonu et al., 2019). Métodos como destilação a vapor ou extração com solventes orgânicos são muito utilizados para extração de metabolitos ativos (Abidin, Hayyan, Hayyan, \& Jayakumar, 2017; Favareto et al., 2019), e que mostram respostas promissoras inibindo o desenvolvimento de fitopatógenos.

Trabalhos como os de Chen et al. (2018) relatam que o uso de etanol como solvente orgânico para extração dos metabolitos secundários de Cur. longa, inibiu o desenvolvimento micelial dos fungos Fusarium graminearum e C. higginsianum em $63,80 \%$ e $34,50 \%$ respectivamente utilizando a concentração de 0,5 mg. $\mathrm{mL}^{-1}$. O mesmo efeito inibitório foi observado por Akter, Islam, Takara, Hossain, \& Sano (2019) em $F$. solani inibindo o crescimento micelial em $80 \%$ na concentração de $128 \mu \mathrm{g} \cdot \mathrm{mL}^{-1}$.

A avaliação dos extratos de C. cajucara, P. marginatum e Cur. longa usando diferentes métodos e solventes orgânicos para a extração é necessária para verificar o efeito destes extratos no desenvolvimento do fitopatógeno Colletotrichum sp. agente causal da antracnose em pimenta-de-cheiro. Vale ressaltar que extratos aquosos e metanólicos, que são considerados polares, podem ter uma mistura maior de moléculas das plantas, devido a alta complexidade de metabólitos secundários produzidos por estas que outros extratos de média e baixa polaridade. Neste sentido novas estratégias de extração devem ser avaliadas.

O efeito curativo dos EF não teve influência na redução da incidência da doença em frutos de pimentade-cheiro, conforme observado no experimento em meio de cultura (Tabela 1). Quando os EF foram aplicados de forma preventiva houve redução da incidência da doença para todos os extratos testados. É possível que o uso preventivo dos extratos pode ter induzido resposta de defesa nos frutos ou inibido a geminação dos conídios.

Metabolitos naturais presentes nos extratos vegetais podem estimular a expressão de respostas defesa nas plantas (Conrath, 2011; Thomas \& Hoorn, 2018), e indução de rotas metabólicas como a do ácido salicílico (SA), ácido jasmônico (JA) e etileno (ET) que ativam a cascata de sinalização que resulta na transcrição de genes de defesa ao ataque de patógenos (Beckers et al., 2009; Balmer, Pastor, Gamir, Flors, \& Mani, 2015).

Shabana et al., (2017) relatam que o uso de nim (Azadirchta indica A. Juss.,) aplicada de maneira preventiva diminuiu o número de pústulas de ferrugem em plantas de trigo em $86,30 \%$, e os autores relacionaram este controle à indução de resistência. Franzener, Schwan-Estrada, Moura, Kuhn, \& Stangarli (2018), avaliaram que o efeito de extrato aquoso de eucalipto (Corymbia citriodora (Hook.,) promoveu a indução a resistência em plantas de pepino contra a antracnose causada pelo patógeno C. lagenarium, devido à síntese de peroxidase $(67,2 \%)$ e $\beta$-1,3-glucanase (122,7\%) e fenilalanina amônia liase (PAL) $(18,5 \%)$ que são enzimas relacionas a indução de resistência em plantas. Draz, Elkhwaga, Elzaawely, El-Zahaby, \& Ismail (2019), observaram que o uso de extratos aquoso de cinco espécies de plantas aplicados em plantas de trigo para o controle da ferrugem (Puccinia triticina Eriks) e as análises bioquímicas mostraram aumento do conteúdo de clorofila a e $b$, fenólicos totais e atividades de enzimas oxidativas em todos os tratamentos testados, estes resultados indicam que os extratos de plantas testados podem induzir resistência do trigo à ferrugem.

É possível que os extratos de C. cajucara, P. marginatum e Cur. longa possam estar relacionados com a ativação de respostas de defesa nos frutos da pimenta-de-cheiro, quando utilizados de maneira preventiva. Trabalhos futuros são necessários visando esclarecer o efeito destes extratos na indução de resistência, ativação de rotas bioquímicas e atividade enzimáticas em pimenta-de-cheiro in vitro e em campo, e garantir que o uso dos extratos de $C$. cajucara, $C$. longa e $P$. marginatum podem ser uma alternativa para o controle da antracnose no Amazonas.

\section{Conclusão}

Os extratos aquosos de Cur. longa, C. cajucara e $P$. marginatum não tem efeito sobre o desenvolvimento in vitro micelial e na produção de conídios de Colletotrichum sp., e não apresentaram efeito 
curativo em frutos de pimenta-de-cheiro. O uso preventivo dos extratos resultou na redução da incidência da doença em 100\%, (Cur. Longa) 66,7\% (P. marginatum) e 58,3\% (C. cajucara), podendo ser uma alternativa futura para o manejo integrado da antracnose no Amazonas.

\section{Declaração de conflito de interesses}

Os autores declaram que não há conflitos de interesse.

Os autores agradecem o apoio da Fundação de Amparo à Pesquisa do Estado do Amazonas FAPEAM pela concessão de bolsa ao primeiro autor. Esse trabalho teve apoio para pesquisa da Coordenação de Aperfeiçoamento de Pessoal de Nível Superior (CAPES) Projeto n 3287/13.

\section{Referências}

Abidin, M.H.Z., Hayyan, M., Hayyan, A., \& Jayakumar, N.S. (2017). New horizons in the extraction of bioactive compounds using deep eutectic solvents: A review. Analytica Chimica Acta 979, 1-23. http://dx.doi.org/10.1016/j.aca.2017.05.012

Akter, J., Islam, M.Z., Takara, K., Hossain, M.A., \& Sano, A. (2019). Isolation and structural elucidation of antifungal compounds from Ryudai gold (Curcuma longa) against Fusarium solani sensu lato isolated from American manatee. Comparative Biochemistry and Physiology 219, 87-94. https://doi.org/10.1016/i.cbpc.2019.02.011

Ali, A., Bordoh, P.K., Singh, A., Siddiqui, Y., \& Droby, S. (2016). Post-harvest development of anthracnose in pepper (Capsicum spp): Etiology and management strategies. Crop Protection 90, 132-141. http://dx.doi.org/10.1016/i.cropro.2016.07.026

Ali, A., Pheng, T.W., \& Mustafa, M.A. (2015). Application of lemongrass oil in vapour phase for the effective control of anthracnose of 'Sekaki' papaya. Journal of Applied Microbiology 118, 1456-1464. https://doi:10.1111/jam.12782

Almeida, L.B., Matos, K.S., Assis, L.A.G., \& Hanada, R.E. (2017). First report of anthracnose of Capsicum chinense in Brazil Caused by Colletotrichum brevisporum. Plant Disease, 101(6), 1035. http://dx.doi.org/10.1016/i.foodcont.2016.09.032

Araújo, E.R., Harand, W., Lima, I.C., Dias, F.C.R., Santana, A.A.D., \& Carvalho, R.R.C.; (2014). Delson Laranjeira, D. Extratos de Piper marginatum e Azadirachta indica no controlede Colletotrichum scovillei em pimentão. Pesquisa Agropecuária Brasileira, Brasília, 49(2), 88-94. https://doi.org/10.1590/S0100204X2014000200002

Azevedo, M.M.B., Almeida, C.A., Chaves, F.C.M., Rodrigues, I.A., Bizzo, H.R., Alviano, C.S., Alviano, D.S. (2016). 7 hydroxycalamenene Effects on Secreted Aspartic Proteases Activity and Biofilm Formation of Candida spp. Phcog Mag 12, 36-40. http://dx.doi.org/10.4103/0973-1296.176022

Azevedo, M.M.B., Almeida, C.A., Chaves, F.C.M., Takaki, G.M.C., Rozental, S., Bizzo, H.R., Alviano, C.S., \& Alviano, D.S. (2014). Effects of 7-Hydroxycalamenene isolated from Croton cajucara essential oil on growth, lipid content and ultrastructural aspects of Rhizopus oryzae. Plant medicinal 80, 550-556.

Balmer, A., Pastor, V., Gamir, J., Flors, V., \& Mani, B.M. (2015). The 'prime-ome': towards a holistic approach to priming. Trends in Plant Science 20, 443-452. https://doi.org/10.1016/i.tplants.2015.04.002

Beckers, G.J.M., Jaskiewicz, M., Liu, Y., Underwood, W.R., He, S.Y., Zhang, S., \& Conrath, U. (2009). Mitogen-Activated Protein Kinases 3 and 6 Are Required for Full Priming of Stress Responses in Arabidopsis thaliana. American Society of Plant Biologists 21, 944-953. http://www.plantcell.org/cgi/doi/10.1105/tpc.108.062158

Berni, R.F., \& Cardoso, M.O. Custos peracionais na cultura de pimenta-de-cheiro e estimativa de renda familiar em várzea do Amazonas. (Documentos 105/2013), Manaus, AM, Embrapa Amazônia Ocidental.

Brú, J., \& Guzman, J.D. (2016). Folk medicine, phytochemistry and pharmacological application of Piper marginatum. Revista Brasileira de Farmacognosia, 26, 767-779. http://dx.doi.org/10.1016/.bip.2016.03.014 
Chen, C., Long, L., Zhang, F., Chen, Q., Chen, C., Yu, X., Liu, Q., Bao, J., \& Long, Z. (2018). Antifungal activity, main active componentes and mechanism of Curcuma longa extract against Fusarium graminearum. Plos One, 13(3), 1-19. https://doi.org/10.1371/journal.pone.0194284

Conrath. U. (2011). Molecular aspects of defence priming. Trends in Plant Science 16, 524-531. http://dx.doi.org/10.1016/i.tplants.2011.06.004

Diao, Y.Z., Fan, J.R., Wang, Z.W., \& Liu, X.L. (2013). First Report of Colletotrichum boninense Causing Anthracnose on Pepper in China. Plant Disease, 97(1), 138. https://doi.org/10.1094/pdis-04-12-0403-pdn

Dorneles, K.R., Pazdiora, P.C., Silva, F.J.A., Moccellin, R., \& Farias. C.R.J. (2018). Control of Bipolaris oryzae (Breda de Haan) using Curcuma longa (Linnaeus) Extract and effect of this extract on rice seed physiology. Revista Caatinga, Mossoró, 31(1), 99-105. https://doi.org/10.1590/1983-21252018v31n112rc

Draz, I.S., Elkhwaga, A.A., Elzaawely, A.A., El-Zahaby, H.M., \& Ismail, A.W.A. (2019). Application of plant extracts as inducers to challenge leaf rust of wheat. Egyptian Journal of Biological Pest Control, 29(6), 1-8. https://doi.org/10.1186/s41938-019-0109-9

Ezeonu, C.S., Tatah, V.S., Imo, C., Mamma, E., Mayel, M.H., Kukoyi, A.J., \& Jeji, I.A. (2019). Inhibitory effect of aqueous and ethanolic extracts of neem parts on fungal rot disease of Solanum tuberosum. Pakistan Journal of Biological Sciences 22, 206-213. https://doi.org/10.1155/2021/6696470

FAO, (2018). Organização das Nações Unidas para Alimentação e Agricultura. Disponível em: www.fao.org/faostat/es/\#data/QC/visualize. Acesso em: 20 de junho de 2020.

Favareto, R., Teixeira, M.B., Soares, F.A.L., Belisário, C.M., Cabral, J.F., Silva, E.A., Moia, T.A., \& CardozoFilho, L. (2019). Extraction of bioactive compounds of leaves of Duguetia furfuracea (annonaceae) using green and organic solvents. Brazilian Journal of Chemical Engineering 36, 549-556. https://doi.org/10.1590/01046632.20190361s20170451

Franzener, G., Schwan-Estrada, K.R.F., Moura, G.S., Kuhn, O.J., \& Stangarli, J.R. (2018). Induction of defense enzymes and control of anthracnose in cucumber by Corymbiacitriodora aqueous extract. Summa Phytopathologica, 44(1), 10-16. https://doi.org/10.1590/0100-5405/2218

Gasparotto, L., Pereira, J.C.R., \& Berni, R.F. (2014). A antracnose da pimenta-de-cheiro. (Comunicado Tecnico 104/2014), Manaus, AM, Embrapa Amazônia Ocidental

Hanada, R.E., Gasparotto, L., Perira, J.C.R., \& Assis, L.A.G. (2011, agosto) Ocorrencia de Colletotrichum sp. em pimenta de cheiro (Capsicum chinense) no Amazonas. Suplemento apresentado no XLIV Congresso Brasileiro de Fitopatologia, Bento Gonçalves, RS, Brasil

Instituto Brasileiro de Geografia e Estatística (2017). Recuperado em 20 de janeiro, 2021 de www.sidra.ibge.gov.br/tabela/6619

Instituto de Desenvolvimento Agropecuário e Florestal Sustentável Do Estado Do Amazonas (2019). Recuperado em 20 de janeiro, 2021 de http://www.idam.am.gov.br/wp-content/uploads/2020/07/RATProdu\%C3\%A7\%C3\%A3o-Vegetal-4\%C2\%BA-Trim-2019.pdf

Liu, F., Tang, G., Zheng, X.; Li, Y., Sun, X., Qi, X., Zhou, Y., Xu, J., Chen, H., Chang, X., Zhang, S., \& Gong, G. (2016). Molecular and phenotypic characterization of Colletotrichum species associated with anthracnose disease in peppers from Sichuan Province, China. Scientific Reports 6, 32761. https://doi.10.1038/srep32761

Ministério de Agricultura Pecuária e Abastecimento. Recuperado em 20 de janeiro, 2021 de http://agrofit.agricultura.gov.br/agrofit_cons/principal_agrofit_cons

Martinez, J., Gomez, A., Ramirez, C., Gil, J., \& Durango, D. (2020). Controlling anthracnose by means of extracts, and their major constituents, from Brosimum rubescens Taub. Biotechnology Reports 25, e00405. https://dx.doi.org/10.1016/i.btre.2019.e00405

Meng, X., Li, J., Bi, F., Zhu, L., \& Ma, Z. (2015). Antifungal Activities of Crude Extractum from Camellia semiserrata Chi (Nanshancha) Seed Cake Against Colletotrichum musae, Colletotrichum gloeosporioides and Penicillium italicum in vitro and in vivo Fruit Test. Plant Pathology Jornal 31, 414-420. https://doi.org/10.5423/PPJ.OA.06.2015.0098 
Mohsan, M., Ali, S., Shahbaz, M.U., Saeed, S., \& BURHAN, M. (2017). In vitro efficacy of different growth media and crude plant extracts against mycelia growth of Phytophthora capsici. Journal of Applied Biology \& Biotechnology 5, 43-47. https://doi.10.1007/s11356-017-0283-9

Nascimento, A.M., Ferreirac, D.M., Souza, E.F.J., Souzaa, L.M., Sassaki, G.L., lacomini, M., Werner, M.F.P., \& Cipriani, T.R. (2017). Gastroprotective effect and chemical characterization of a polysaccharide fraction from leaves of Croton cajucara. International Journal of Biological Macromolecules, 95, $153-159$. http://dx.doi.org/10.1016/i.ijbiomac.2016.11.044

Nazzaro, F., Fratianni, I.F., Coppola, I.R., \& De Feo, V. (2017). Essential Oils and Antifungal Activity. Pharmaceuticals 10, 86. https://doi.org/10.3390/ph10040086

Oliveira, C.V.S., Matos, K.S., Albuquerque, D.M.C., Hanada, R.E., \& Silva, G.F. (2017). Identification of Colletotrichum isolates from Capsicum chinense in Amazon. Genetics and Molecular Research, 16(2), 1-10. https://doi.org/10.1007/s10658-019-01879-9

Pagano, E., Romano, B., Izzo, A.A., \& Borrelli, F., (2018). The clinical efficacy of curcumin-containing nutraceuticals: An overview of systematic reviews. Pharmacological Research, 134, 79-91. https://doi.org/10.1016/i.phrs.2018.06.007

Park, J.Y., Kim, S.H., Kim, N.H., Lee, S.W., Jeun, Y.C., \& Hong, J.K. (2017). Differential Inhibitory Activities of Four Plant Essential Oils on In Vitro Growth of Fusarium oxysporum f. sp. fragariae Causing Fusarium Wilt in Strawberry Plants. Plant Pathology Jornal 33, 582-588. https://doi.org/10.5423/PPJ.OA.06.2017.0133

Ranathunge, N.P., Mongkolporn, O., Ford, R., \& Taylor, P.W.J. (2012). Colletotrichum truncatum Pathosystem on Capsicum spp: infection, colonization and defence mechanisms. Australasian Plant Pathology 41, 463-473. https://dx.doi.10.1007/s13313-012-0156-0

Equipe RStudio (2020). Desenvolvimento integrado para R. RStudio, (Versão 4.0.2). [Software estatístico] PBC, Boston, MA. Recuperado de http://www.rstudio.com/

Saini, T.J., Gupta, S.G., \& Anandalakshmi, R. (2017). Detection of chilli anthracnose caused by Colletotrichum cliviae in India. Australasian Plant Disease Notes, 12(33), 1-4. https://doi.10.1007/s13314-017-0260-7

Sganzerla, M., Coutinho, J.P., Melo, A.M.T., \& Godoy, H.T. (2014). Fast method for capsaicinoids analysis from Capsicum chinense fruits. Food Research International 64, 718-725. http://dx.doi.org/10.1016/i.foodres.2014.08.003

Shabana, Y.M., Abdalla, M.E., Shahinb, A.A., El-Sawy, M.M., Draz, I.S., \& Youssif, A.W. (2017). Efficacy of plant extracts in controlling wheat leaf rust disease caused by Puccinia triticina. Egyptian Journal of Basic and Applied Sciences, 4(1), 67-73. http://dx.doi.org/10.1016/i.eibas.2016.09.002

Sun, Y., Wang, Y., Han, L.R., Zhang, X., \& Feng, J.T. (2017). Antifungal Activity and Action Mode of Cuminic Acid from the Seeds of Cuminum cyminum L. against Fusarium oxysporum f. sp. Niveum (FON) Causing Fusarium Wilt on Watermelon. Molecules 22, 2053. https://dx.doi.org/10.3390/molecules22122053

Suwor, P., Thummabenjenjapane, P., Sanitchon, J., Kumar, S., \& Techawongstien, S. (2015). Phenotypic and genotypic responses of chili (Capsicum annuum L.) progressive lines with different resistant genes against anthracnose pathogen (Colletotrichum spp.). European Journal of Plant Pathology 143, 725-736. https://doi.10.1007/s10658-015-0723-7

Thomas, E.L., \& Hoorn, R.A.L. (2018). Ten Prominent Host Proteases in Plant-Pathogen Interactions. International Journal of Molecular Sciences 19, 639. http://dx.doi.org/10.3390/ijms19020639

Tyskiewicz, K., Tyskiewicz, R., Konkol, M., Rój, E., Sciseł, J.J., \& Wozniak, K.S. (2019). Antifungal Properties of Fucus vesiculosus L. Supercritical Fluid Extract Against Fusarium culmorum and Fusarium oxysporum. Molecules 24, 3518. https://dx.doi.org/10.3390\%2Fmolecules22111914

Wang, Y., Zhang, J., Sun, Y., Feng, J., \& Zhang, X. (2017). Evaluating the Potential Value of Natural Product Cuminic Acid against Plant Pathogenic Fungi in Cucumber. Molecules 22, 1914. https://dx.doi.org/10.3390\%2Fmolecules22111914

Wheeler, B.E.J.(1969). An Introduction of Plant Diseases. London, United Kingdom. 